\title{
Effect of Temperature, Pressure and Moisture Content on Durability of Cattle Manure Pellet in Open-end Die Method
}

\author{
Abedin Zafari (Corresponding author) \\ Graduate student of department of agrotechnology, College of Abouraihan \\ University of Tehran, Tehran, Iran \\ Tel: 98-918-850-1031Ｅ-mail: abedinzafari@ut.ac.ir \\ Mohammad Hosein Kianmehr \\ Associate professor of department of agrotechnology, College of Abouraihan \\ University of Tehran, Tehran, Iran \\ E-mail: kianmehr@ut.ac.ir
}

$\begin{aligned} & \text { Received: February 6, } 2012 \quad \text { Accepted: February 20, } 2012 \quad \text { Online Published: April 1, } 2012 \\ & \text { doi:10.5539/jas.v4n5p203 }\end{aligned} \quad$ URL: http://dx.doi.org/10.5539/jas.v4n5p203

\begin{abstract}
Densification of biomass feedstocks, such as pelleting, can increase bulk density, improve storability, reduce transportation costs, and make these materials easier to handle by using existing handling and storage equipment. Evaluation effect of extrusion and raw material parameters on quality parameters of pellet is necessary to determine optimum conditions for designing and constructing a suitable pelleting machine for producing cattle manure pellets. In this study durability of cattle manure pellet that produced by opened die method determined at different temperatures $(T)$, pressures $(P)$ and moisture contents $\left(\mathrm{M}_{\mathrm{w}}\right)$. Cattle manure samples were compressed with three levels of pressures $(3.5,6$ and $8 \mathrm{Mpa})$ and three levels of temperatures $\left(40,60\right.$ and $\left.80{ }^{\circ} \mathrm{C}\right)$ at three levels of moisture contents (50, 55 and 60\%). ANOVA results have indicated that linear terms $\mathrm{T}, \mathrm{P}$ and $\mathrm{Mw}$ and interaction of variables were statistically significant at $\mathrm{P}<0.01$ for pellet durability. Also using cattle manure with $50 \%$ moisture content, medium temperature about $40{ }^{\circ} \mathrm{C}$ and pressure at $6 \mathrm{MPa}$ resulted maximum pellet durability.
\end{abstract}

Keywords: Biomass pellet, Open-end die, Durability, Extrusion parameters

\section{Introduction}

Livestock refuse is important secondary production in cattleman. Livestocks refuse (contain of cattle manure and bed manure) is a valuable source of mineral matter (Nitrogen $1.78 \%$, Phosphor $0.5 \%$ and Potassium $0.99 \%$ ) for plants. About 6 million tons cattle manure have produced in Iran that usually stockpile in cattleman. According to shortage organic material in field, use of cattle manure increases the agricultural production yield. On the other hand, cattle manures are naturally low-density materials and, therefore, the application of a form of densification would increase their utility. The densification process and pellet production is able to convert manure into a compressed form with advantages in transportation, handling and storage (Bhattacharya et al., 1989). Biomass densification means the use of some form of mechanical pressure to reduce the volume of biomass material and the conversion of this material to a solid form (Erickson and Prior, 1990). There are two kinds of molding machine available on the market which shape composted livestock manure into pellets. One kind is the

diskpelleter (dry molding method), and the other is the extruder type (wet molding method). Molding machines of the extruder type have a barrel into which the raw material is forced by a screw. The material is then compressed into the die installed at the end of the machine, producing the pellet. This method has several benefits. The temperature can be controlled by adjusting the pressure, while it is easy to make pellets of various shapes by simply replacing the die.

One of the requirements to design, construct or improve designs in densification systems is based mainly of the 
knowledge on suitable levels of process variables (die geometry, relaxation time, die and material temperature and pressure) and of material variables (content and distribution of moisture, size and shape of particles, size distribution of particles, biochemical and mechanical characteristics) (Rehkugler and Buchele, 1969). Due to the importance of problem in recent years much research has been done about densification of biomass material. Bhattacharya (1989) compared densification in hot and high-pressure conditions and densification in cold and low-pressure conditions in terms of quality of the product, and power consumption. Bilansky et al. (1985) carried out their experiments in a cylindrical closed die. Chen et al. (1989) designed a laboratory pelletizer operated with an Universal Testing Machine for compression tests. This pelletizer was also designed to control temperature and pressure, Zohns and Jenkins (1986), Esaki et al. (1986), Faborode and O'Callaghan (1986) also have carried out experiments with closed dies in the laboratory. In the same way, O'Doguerty and Wheeler (1984) used a closed die for testing the bulk compression of wheat straw. An interesting open-end die was used by Payne et al. (1973). The open-end die was designed to control temperature of the die, retention time and moisture content of chicken excreta.

The objective of this work was to analyse the influence of different levels of temperature, pressure and moisture content on the durability of cattle manure pellets and develop the knowledge required to optimize the design and operation of extruder. An open-end die was used to simulate the extrusion process.

\section{Material and Method}

\subsection{Sample Preparation}

Manure used in this study was obtained animal husbandry around the Tehran. Before pelleting, the manure samples were ground using a hammer mill. Then samples were wetted by sprinkling water on them moisture content of 50, 55 and $65 \%$ (w.b) and stored in a cooler at $4{ }^{\circ} \mathrm{C}$ for a minimum $72 \mathrm{~h}$. The moisture content of the ground samples was determined following the procedure given in ASTM standard for coal and coke (ASTM, 1998). Particle size distribution of manure determined by using the sieves that arranged from the largest to the smallest opening. American series sieve numbers 10,16,30 and 50 (sieve sizes: 2,1,0.6 and $0.3 \mathrm{~mm}$, respectively) were used. The experiments were performed for all levels of particle size (mesh 10 to 50) but due to lack of initial stability in the 10,16 and 30 mesh size only 50 mesh size were considered.

\subsection{Pelleting}

The laboratory equipment to produce pellet included a hydraulic press (Figure 1), and an open-end die (Figure 2). This die offers a better way to reproduce the extrusion process than closed dies. Typical extruder includes multiple extrusion holes arranged on a flat die. The laboratory die is trying to simulate the extrusion by using only one hole $(6 \mathrm{~mm})$ in real scale. So, similar conditions of extrusion process have to be reached in order to reproduce the extrusion process. The die used includes a pre-compression section with the compression ratio 5:1. The die temperature was controlled through use of an electrical heater fitted around the die. A type-K thermocouple was placed in a hole made in the die and it was used to control the die temperature. After the die temperature was reached, ten minutes were allowed before the experimental run. To provide the piston moves a hydraulic press was used. This press have three important features: pressure control, piston speed control and residence time control in set pressure. The hydraulic press was adapted with a data recording system for displacement, force and time. By moving the piston inside to cylinder die material is compressed and convert to pellet when out of the die. Piston speed during the tests was constant and equal $10 \mathrm{~mm} / \mathrm{s}$. Produced pellets were dried at ambient temperature until their moisture content reached under $11 \%$.

\subsection{Durability of pellets}

Durability, defined as the ability of pellets to withstand destructive loads and force during transport, is the most important physical quality of a pellet (Tabil and Sokhansanj, 1996). Durability is considered high when the computed value is above $80 \%$, medium when the value is between $70 \%$ and $80 \%$, and low when the value is below $70 \%$ (Colley et al., 2006). Low pellet durability is not desirable as it can cause problems such as disturbance within pellet feeding systems, dust emissions, and an increased risk of fire explosion during pellet handling and storage. Pellet durability was determined according to ASAE Standards S269.4. Based on the standard, moisture content of samples should be about $11 \%$ and length of them should be three times their diameter. A 500-g sample of sieved pellets was tumbled at $50 \mathrm{rpm}$ for $10 \mathrm{~min}$ in a dust-tight enclosure. After tumbling, the sample was removed and sieved, and the percentage of whole pellets was calculated using the following formula: 


$$
\text { Durability }(\%)=\frac{\text { Mass of pellet after tumbling }}{\text { Mass of pellet befor tumbling }} \times 100 \%
$$

\subsection{Statistical Methods}

All experiments for each biomass sample were carried out in triplicate. Data were analyzed

by using the analysis of variance (ANOVA) and Duncan's multiple test at the 0.01 level procedures in SAS statistical software package.

\section{Result and Discussion}

The ANOVA analysis (Table 1) shows that main effect of temperature, pressure and moisture content and interaction effect of variables on pellets durability were statistically significant at $\mathrm{P}<0.01$.

In figure. 3 effect of temperature on durability of pellets is shown. With increasing temperature from 40 to $80^{\circ} \mathrm{C}$ pellets durability decrease from 93.51 to $90.84 \%$. With increasing temperature molecular movement increased that prevents sticking of molecules inside the pellet consequently pellet durability decrease.

In figure. 4 effect of moisture content on durability of pellets is shown. With increasing moisture content from 50 to $60 \%$ pellets durability decrease from 94.75 to $89.51 \%$. the increase of moisture from a limit reduces the intermolecular forces, and even, too much moisture content causes a biphasic mixture (liquid phase and solid phase) and disappears entirely intermolecular forces.

Also moisture increase cause rheological properties of manure change from viscoplastic to viscoelastic, and because pellet drying is not instantaneous phenomenon there is the possibility of disintegration pellets.

In figure. 5 effect of pressure on durability of pellets is shown. With increasing pressure from 3.5 to $60 \mathrm{Mpa}$ pellets durability increase from 90.93 to $93.01 \%$ and pressure increase to 8 Mpa decrease the durability to $92.24 \%$. The increase of pressure will cause approach the particles to each other, thus the apparent pellet density and the molecular forces between particles increases that increases the durability of pellets. Excessive pressure increase, due to creation of residual stress in the pellets decrease the pellets durability when out of the die.

Interaction effect of temperature and moisture content on durability of pellet is shown in figure. 6 . In all levels of pressure by increase of moisture content the durability decrease and maximum durability there is in $40{ }^{\circ} \mathrm{C}$ temperature an $50 \%$ moisture content.

Interaction effect of temperature and pressure on durability of pellet is shown in figure. 7.

Figure shows that with increase of temperature at constant pressure the durability of pellets decrease. This figure also shows that effect of pressure change on durability at 60 and $80{ }^{\circ} \mathrm{C}$ temperatures is more significant than $40{ }^{\circ} \mathrm{C}$ temperature.

Interaction effect of moisture content and pressure on durability of pellet is shown in figure. 8 .

This figure shows that in all levels of moisture content by increase of pressure in first durability increase and then decrease.

\section{Conclusions}

The open-end die method because it is a continuous method to production of pellets, according to the result are known as an effective way to production manure pellet. Use of this laboratory method in the present study was very useful to determine effect of extrusion and raw material properties on durability of pellet as important quality parameter of pellet. The present work examined the effects of temperature, pressure and moisture content on the durability of cattle manure pellets. It was found that all these variables significantly affected pellet durability.

\section{References}

ASAE Standards. (1998). S269.4 Cubes, Pellets and Crumbles-Definitions and Methods for Determining Density,Durability and Moisture Content ASAE DEC96. Standard S358.2 Moisture Measurement-forages. ASAE, St. Joseph, MI.

ASTM Standards. (1998). ASTM Standards D 3173-87-Standard Test Method for Moisture in the Analysis Sample of Coal and Coke. ASTM, West Conshohocken, PA, USA., pp: 301-302.

Bhattacharya, S. C., Sett, S, \& Shrestha, R M. (1989). State of the Art of Biomass Densification, Energy Sources, Division of Energy Technology, Vol. 11(3), pp 161-186. Taylor \& Francis, New York.

Bhattacharya, S. C. (1989). State of the Art of Biomass Densification. Division of Energy Technology. Energy 
Sources, N. Y., Taylor and Francis. 11 (3), 161-186.

Bilanski, W. K., Graham, V. A. \& Hanusiak, J. A. (1985). Mechanics of Bulk Forage Deformation with Application to Wafering. Transactions of the ASAE, 28(3), 697-702.

Chen, P., Haygreen, J. G. \& Graham, M. A. (1989). An Evaluation of Wood/coal Pellets made in a Laboratory Pelletizer. Forest Products Journal, 39(7/8), 53-58.

Colley, Z., Fasina, O. O., Bransby, D., \& Lee, Y. Y. (2006). Moisture effect on the physical characteristics of switchgrass pellets. TASAE, 49, 1845-1851.

Erickson, S. \& Prior, M. (1990). The Briquetting of Agricultural Wastes for Fuel. FAO Environment and energy paper 11. FAO, Via delle Terme di Caracalla, 00100 Rome, Italy.

Esaki, H., Satake, T. \& Guo, K. (1986). Research on the Pelletization of Biomass (Part II). Compressive Characteristics on the Forming of the Pellet and Wafer. Journal of the Japanese Society of Agricultural Machinery, 48(1), 83-90.

Faborode, M. O. \& O'Callaghan, J. R. (1986). Optimizing the Compression/Briquetting of Fibrous Agricultural Materials. Journal of Agricultural Engineering Research. London Academic Press. 38(4), 245-262. http://dx.doi.org/10.1016/0021-8634(87)90092-8

O'Doguerty, M. J. \& Wheeler, J. A. (1984). Compression of Straw to High Densities in Closed Cylindrical Dies. The British Society for Research in Agricultural Engineering. UK. 29(29), 61-72.

Payne, F. A., Ross, I. J., Hamilton, H. E. \& Fox, J. D. (1973). Short Time, High Temperature Extrusion o Chicken Excreta. Transactions of the ASAE. Paper No. 72 - 450.

Rehkugler, G. E. \& Buchele, W. F. (1969). Biomechanics of Forage Wafering. Transactions of the ASAE. 12(1), $1-8,12$.

Tabil, L., \& Sokhansanj, S. (1996). Process conditions affecting the physical quality of alfalfa pellets. Appl. Eng. Agric., 12 (3), 345-350.

Zohns, M. A. \& Jenkins, B. M. (1986). An Automatic Laboratory Apparatus for Densification of Particulate Materials. ASAE paper No. 86-6578. 1986 Winter Meeting of ASAE. ASAE, St. Joseph, MI.

Table 1. Analysis of variance (ANOVA) table for factors affecting durability of manure pellets

\begin{tabular}{|c|c|c|c|}
\hline Source of variation & DF & MS & SS \\
\hline $\mathrm{T}$ & 2 & $49.08^{* *}$ & 98.163 \\
\hline $\mathrm{P}$ & 2 & $185.28^{* *}$ & 370.554 \\
\hline $\mathrm{M}_{\mathrm{w}}$ & 2 & $29.80^{* *}$ & 59.593 \\
\hline $\mathrm{T} \times \mathrm{M}_{\mathrm{w}}$ & 4 & $1.90^{* *}$ & 7.600 \\
\hline $\mathrm{T} \times \mathrm{P}$ & 4 & $3.03^{* *}$ & 12.119 \\
\hline $\mathrm{M}_{\mathrm{w}} \times \mathrm{P}$ & 4 & $1.22^{* *}$ & 4.875 \\
\hline $\mathrm{T} \times \mathrm{M}_{\mathrm{w}} \times \mathrm{P}$ & 8 & $1.41^{* *}$ & 11.305 \\
\hline Error & 54 & 0.0126 & \\
\hline
\end{tabular}

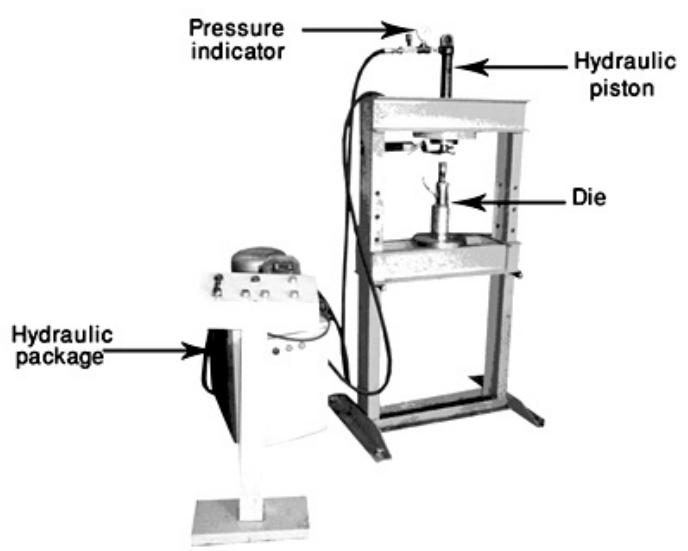


Figure 1. Hydraulic pres

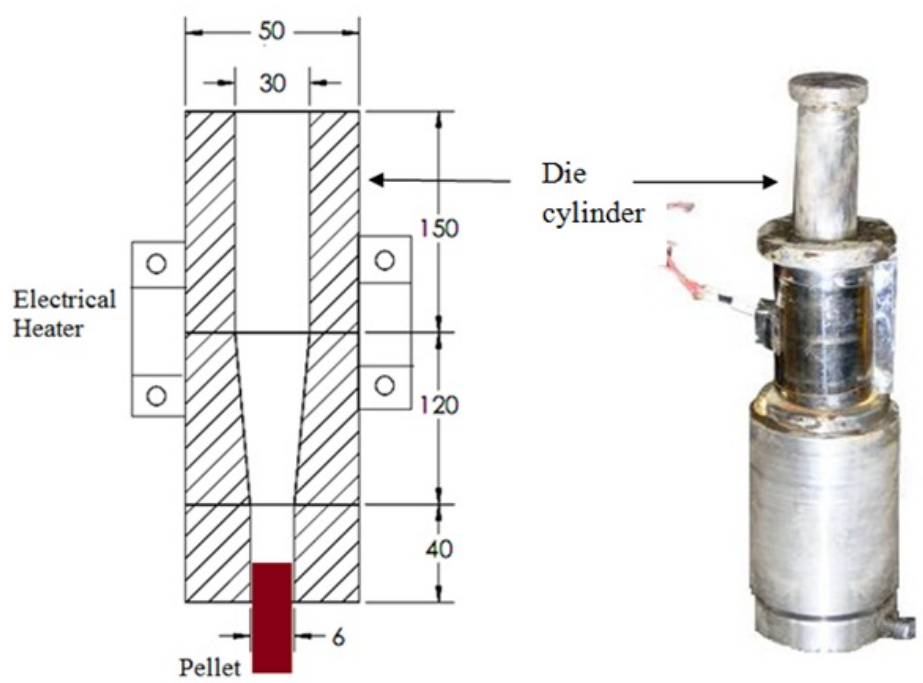

Figure 2. Densification open-end die (all dimension is $\mathrm{mm}$ )

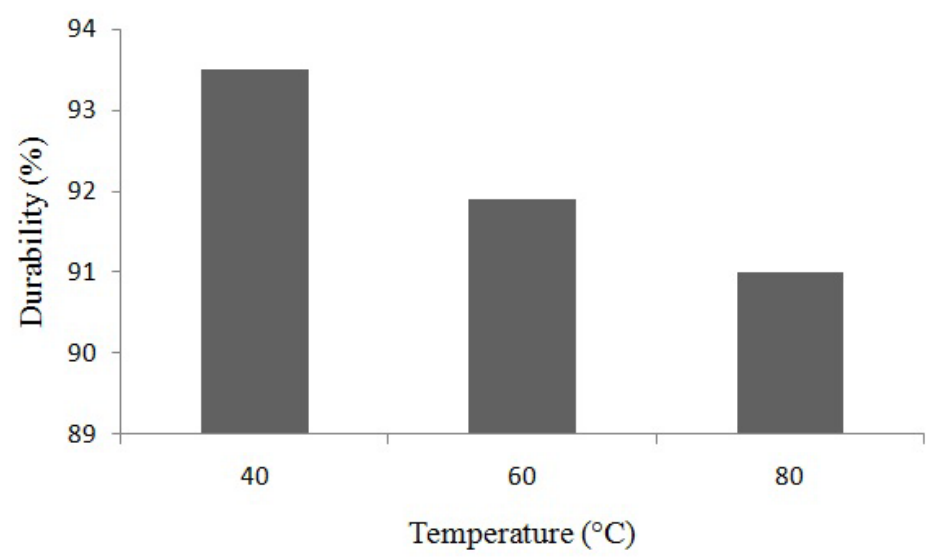

Figure 3. Effect of temperature on pellet durability

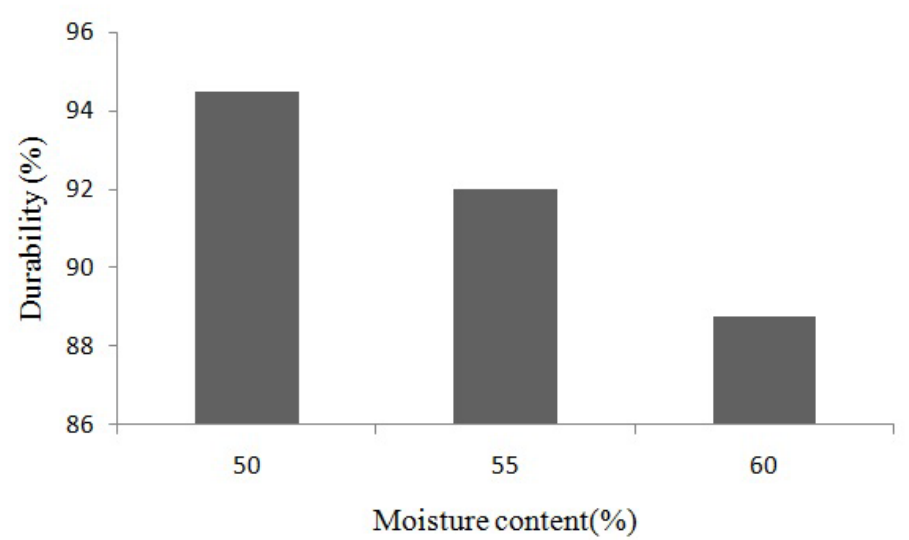

Figure 4. Effect of moisture content on pellet durability 


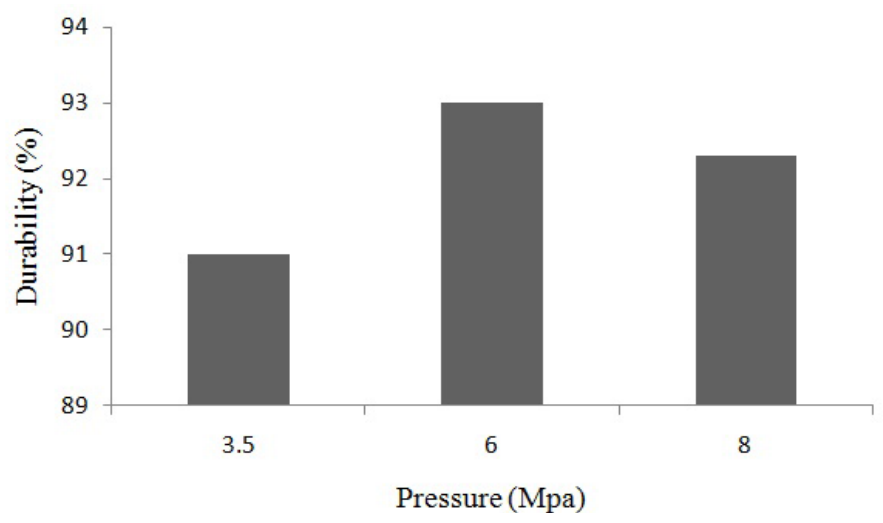

Figure 5. Effect of pressure on pellet durability

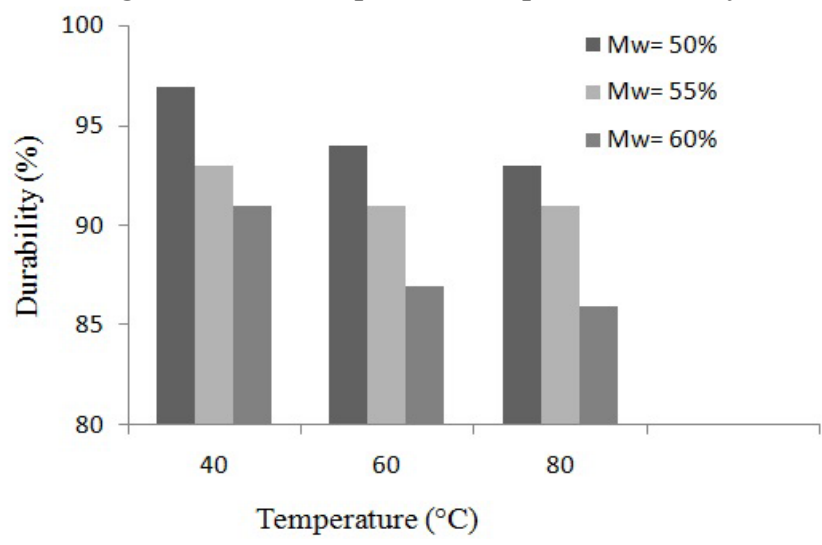

Figure 6. Interaction effect of temperature an moisture content on pellet durability

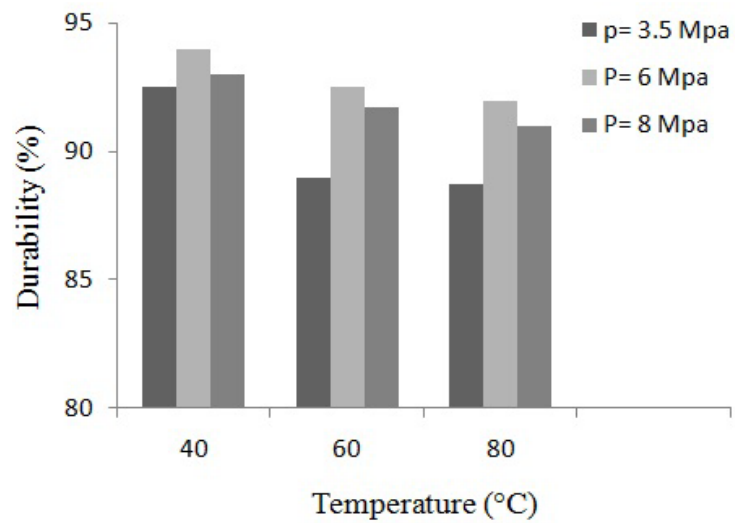

Figure 7. Interaction effect of temperature and pressure on pellet durability

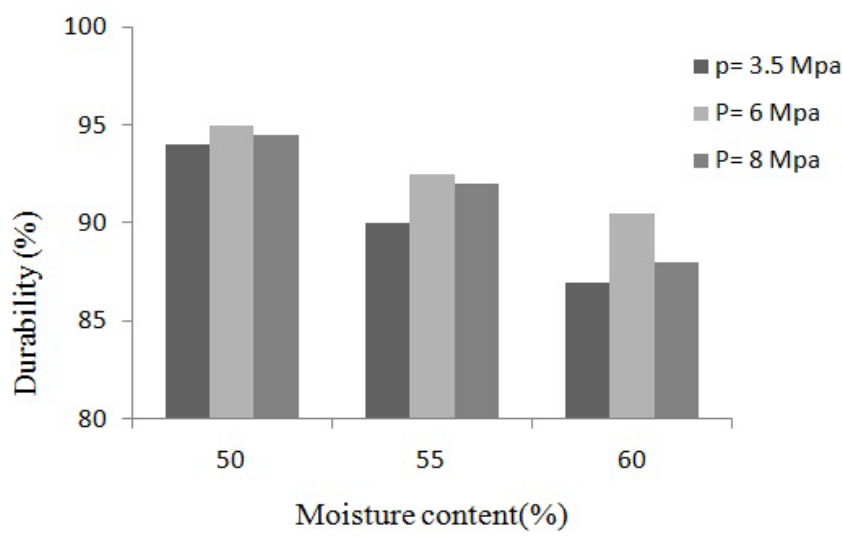

Figure 8. Interaction effect of pressure and moisture content on pellet durability 